\title{
Adubação nitrogenada beneficia soja alagada
}

\author{
Luciana Nunes Menolli Lanza (*); Sarita Carneiro Rossi; Ladaslav Sodek \\ Universidade Estadual de Campinas (UNICAMP), Departamento de Biologia Vegetal, Rua Monteiro Lobato, 255, $13083-862$ \\ Campinas (SP), Brasil. \\ (*) Autora correspondente: lucianamenolli@yahoo.com.br
}

Recebido: 2/maio/2012; Aceito: 15/fev./2013

\section{Resumo}

Este trabalho teve como objetivo comparar o desenvolvimento de cinco cultivares de soja produzidas no Estado de São Paulo, em situação de alagamento do sistema radicular, e avaliar a resposta das plantas ao nitrato nessa situação. No trabalho, foram analisadas a área foliar, a massa seca da parte aérea, o volume do sistema radicular e a massa seca do sistema radicular das cultivares de soja IAC Foscarin-31, IAC-23, IAC-17, IAC-24 e IAC-18, além de análise histológica do caule e da raiz principal da cultivar IAC-23, das plantas mantidas durante 28 dias alagadas. Todas as cultivares foram submetidas aos tratamentos: alagamento do vaso sem nitrato; alagamento com nitrato e alagamento com nitrato adicionado após sete dias de experimento. Os resultados indicam que a escolha da cultivar e a adição de nitrato devem ser levadas em consideração para o plantio em regiões com potencial para alagamento. A presença de nitrato foi benéfica para as cinco cultivares avaliadas. Na cultivar IAC-24 notou-se maior crescimento em presença de nitrato. A adição de nitrato sete dias após alagamento promoveu maior crescimento na cultivar IAC Foscarin-31. A presença de aerênquima no caule e na raiz principal de plantas alagadas foi constatada em todos os tratamentos, porém houve variação no arranjo das células parenquimáticas, o qual foi mais compacto nos tratamentos com nitrato.

Palavras-chave: encharcamento, Glycine max, nitrogênio, crescimento vegetal.

\section{Nitrogen fertilization benefits soybean under flooding conditions}

\begin{abstract}
The aim of this study was to compare the growth of five cultivars of soybean produced in the State of São Paulo under conditions of flooding and evaluate the response of the plants to nitrate under such conditions. The study involved the analysis of leaf area, shoot dry mass, volume of the root system and root dry mass, using the soybean cultivars IAC Foscarin-31, IAC-23, IAC-17, IAC-24 and IAC-18, as well as a histological analysis of the stem and main root of the cultivar IAC-23, after being maintained for 28 days under flooding conditions. All cultivars were submitted to the following treatments: flooding of the root system without nitrate; flooding in the presence of nitrate; and flooding with nitrate added seven days after flooding. Our data indicate that the choice of cultivar and the use of nitrate should be taken into account for the planting of soybean in regions subject to flooding. The presence of nitrate during flooding was beneficial for all five cultivars tested. The cultivar IAC-24 presented the highest growth in the presence of nitrate. IAC Foscarin-31 was the most responsive cultivar to the addition of nitrate seven days after flooding, when considering plant growth. The presence of aerenchyma on the stem and main root of the flooded plants was observed for all treatments. However, variation occurred in the arrangement of parenchyma cells, this being more compact in the treatments with nitrate.
\end{abstract}

Key words: waterlogging, Glycine max, nitrogen, plant development.

\section{INTRODUÇÃO}

O Brasil é o segundo maior produtor de soja do mundo com produção de 69,23 milhôes de toneladas na safra 2011/2012 (CONAB, 2012). Devido à grande expansão da soja, em muitas regiōes, sua produção é afetada por diversos fatores climáticos, os quais promoveram a redução de $8,1 \%$ na colheita de soja da safra de 2011/2012 em relação à safra anterior, segundo CONAB (2012).

$\mathrm{O}$ alagamento dos solos é um fator resultante principalmente de solos compactados ou com deficiência de drenagem natural. A salinização e o alagamento dos solos afetam 80 milhôes de hectares das terras mundiais (IBAMA, 2012). Apesar da ausência de dados oficiais sobre as principais regióes afetadas pelo alagamento no Brasil, sabe-se que esse é um fator que prejudica a produtividade agrícola, principalmente quando ocorre no período reprodutivo das plantas ou na época de colheita dos grãos. No Estado do Rio Grande do Sul, muitos estudos com plantas de soja em áreas alagadas são realizados, e todos eles comparando plantas alagadas com não alagadas, dentre eles, Pires et al. (2002) e Zenzen et al. (2007). Esses trabalhos possuem a finalidade de buscar alternativas de manejo para cultivos nas várzeas 
arrozeiras, proporcionando maior retorno econômico (Pires et al., 2002).

Em solos alagados ocorre estresse por hipoxia (concentração insuficiente de oxigênio para manter a taxa normal de respiração da raiz), uma vez que a taxa de difusão do oxigênio na água é $10^{4}$ vezes menor que no ar (Armstrong et al., 1994). Consequentemente, esse estresse afeta o desenvolvimento da planta (FANTE et al., 2010).

Algumas plantas possuem tolerância (aptidão da planta para enfrentar um ambiente desfavorável) ao alagamento, e esta tolerância depende da intensidade, duração do estresse e do tipo de solo. Pires et al. (2002) e ZENZEN et al. (2007) utilizaram a palavra adaptação (nível de resistência geneticamente determinado adquirido por um processo de seleção durante muitas geraçōes) e consideram a cultivar com maior desenvolvimento quando alagada como mais adaptada ao alagamento. Em seus trabalhos, a cultivar de soja FT-Abyara foi considerada mais adaptada ao alagamento por sua maior área foliar, massa seca da parte aérea e do sistema radicular e maior volume do sistema radicular que a cultivar BR 4, considerada mais sensível.

Estudos demonstram que adicionar nitrato $\left(\mathrm{NO}_{3}^{-}\right)$quando as plantas estão alagadas promove maior tolerância das plantas (inclusive a soja) à hipoxia (Malavolta, 1954; Trought e Drew, 1981; Thomas e Sodek, 2005). Teoricamente, esse processo ocorre uma vez que a reduçáo do nitrato promove regeneração do $\mathrm{NAD}^{+}$(Brandâo e Sodek, 2009). Dados recentes indicam que a redução do nitrito, produto da redução do nitrato, ao óxido nítrico também seja importante na regeneração do $\mathrm{NAD}^{+}$ (Oliverra et al., 2013). O nitrato é acrescentado apenas a 2,46\% dos solos brasileiros destinados ao cultivo de soja, não sendo uma prática corriqueira (Borkert et al., 1994), mas sua utilização pode reduzir os danos provocados pelo alagamento. Nesse contexto, avaliamos se a adição de nitrato é benéfica às plantas de soja em situação de alagamento e se a intensidade da resposta ao nitrato varia com a cultivar. Comparando cinco cultivares de soja produzidas no Estado de Sáo Paulo, em condiçóes de alagamento, identificou-se a cultivar com maior desenvolvimento e melhor resposta à adição de nitrato em meio alagado. O desenvolvimento das plantas foi mensurado a partir de análises de parâmetros de desenvolvimento e de análises das modificaçóes na anatomia do caule e da raiz principal.

\section{MATERIAL E MÉTODOS}

O trabalho foi realizado de agosto de 2009 a julho de 2010, em casa de vegetação, no município de
Campinas (SP), a 4703'W e 22048'S; 640 m de altitude. As cultivares de soja utilizadas no experimento foram IAC Foscarin-31, IAC-23, IAC-17, IAC-24 e IAC-18. Três sementes de cada cultivar foram plantadas em vasos com vermiculita e após 10 dias foi realizado o desbaste, permanecendo uma planta por vaso durante todo o experimento. As plantas foram nutridas duas vezes por semana com solução de Hoagland e Arnon (1938).

Quando as plantas atingiram o estádio V4 de desenvolvimento (terceiro trifólio aberto, de acordo com Yorinori, 1996), o experimento foi instalado. Dispuseram-se os vasos com as plantas dentro de outro vaso maior náo perfurado e adicionou-se a eles: solução nutritiva sem nitrato (tratamento sem nitrato); solução nutritiva com nitrato (tratamento com nitrato); e solução nutritiva com adição de nitrato apenas no sétimo dia de alagamento (tratamento nitrato adicionado). Os vasos foram completados com solução nutritiva de Hoagland e Arnon (1938) 1/3 diluída (5 mM de $\mathrm{NO}_{3}^{-}$), a qual era trocada a cada sete dias. Todos os tratamentos foram realizados utilizando-se plantas em situação de alagamento.

As coletas foram realizadas com 0 e 28 dias de tratamento e após esse período, avaliaram-se a área foliar, através de medidor de área foliar, marca Li-cor modelo Li-3100; a massa seca da parte aérea e do sistema radicular, utilizando estufa com circulaçáo de ar a $50^{\circ} \mathrm{C}$ durante 4 dias; volume do sistema radicular, através do deslocamento de água da proveta, e análise histológica. Para a representação dos resultados em gráficos, os valores plotados referem-se ao resultado obtido da subtração do valor mostrado no início do estudo.

Visando compreender o que ocorreu nos tecidos das plantas alagadas, como forma de entender as variaçóes no crescimento e na estrutura delas, escolheu-se a cultivar IAC-23, para analisar histologicamente. De acordo com as observaçóes visuais realizadas durante o experimento, em todas as cultivares ocorrem as mesmas modificaçóes teciduais, porém em intensidades diferentes; por esta razão, a análise de apenas uma cultivar permite inferir informaçóes sobre as demais cultivares. A cultivar IAC-23 foi a escolhida por ter características intermediárias de desenvolvimento. As estruturas anatômicas foram avaliadas com 28 dias. As plantas-controle foram mantidas não alagadas em vasos, enquanto as plantas dos demais tratamentos continuaram alagadas; após 28 dias, foram coletados o caule $(5 \mathrm{~mm}$ acima e abaixo do nó cotiledonar) e a raiz principal (apenas a região formada após o início do experimento).

O caule e a raiz principal foram fixados de acordo com Johansen (1940). As amostras foram desidratadas e incluídas em glicolmetacrilato e as seçóes transversais, obtidas segundo FEDER e O'Brien (1968). Observaçóes e fotografias digitais foram realizadas em microscópio acoplado à câmara digital. 
O delineamento experimental foi inteiramente ao acaso, com três tratamentos (alagamento do vaso sem nitrato; alagamento do vaso com nitrato; e alagamento do vaso com nitrato adicionado apenas no sétimo dia de análise) e sete repetiçóes. Para verificar se houve diferença entre os três tratamentos para a mesma cultivar e diferença entre as cultivares para o mesmo tratamento, na área foliar, na massa seca da parte aérea, no volume do sistema radicular e na massa seca do sistema radicular, os resultados foram submetidos à análise de variância e as médias comparadas pelo teste Tukey com $1 \%$ de probabilidade, exceto os resultados de análise histológica.

\section{RESULTADOS E DISCUSSÃO}

O crescimento da parte aérea foi beneficiado pela adição de nitrato em todas as cultivares testadas. A área foliar das plantas submetidas aos tratamentos em presença de nitrato foi maior que a das plantas submetidas ao tratamento sem nitrato (Figura 1). A cultivar IAC-17 ganhou maior área foliar no tratamento com nitrato, em relaçấo a todas as outras cultivares. A cultivares IAC Foscarin-31, IAC-23 e IAC-17 tiveram as maiores áreas foliares no tratamento com nitrato adicionado. Curiosamente, quando comparados os tratamentos com nitrato e nitrato adicionado, observou-se maior variação na cultivar IAC-24, a qual a área foliar foi $37,6 \%$ maior no tratamento com nitrato. A cultivar IAC Foscarin-31 teve área foliar 32,8\% superior no tratamento com nitrato adicionado. Nas demais cultivares testadas, verificou-se aumento na área foliar nos dois tratamentos em que foi adicionado o nitrato, e nâo foi identificada diferença significativa entre eles. O aumento da área foliar em presença do nitrato já foi observado em mudas de pau ferro alagadas durante 28 dias em presença de nitrogênio, (LenHARD et al., 2010) e em plantas de soja da cultivar FT-Abyara supridas por três fontes de nitrogênio quando o solo foi alagado (Thomas e Sodek, 2005).

Os valores obtidos para massa seca da parte aérea corroboram com os resultados de área foliar, e foram maiores em todas as cultivares em presença do nitrato (Figura 2). Resultados similares foram observados em plantas de curauá quando alagadas durante 20 dias (REIS et al., 2007). A cultivar IAC-24 proporcionou o maior valor de massa seca da parte aérea no tratamento com nitrato, seguida pelos valores observados para IAC-23 e IAC-17. Comparando as cultivares IAC-24 e IAC-17 com relação à área foliar e à massa seca da parte aérea no tratamento com nitrato, observa-se que a IAC-24 pode ter direcionado recursos para o desenvolvimento de outras partes da planta como o caule, ou para aumento da espessura das folhas, o que explicaria a maior massa seca e menor área foliar observada nesta cultivar. Também de
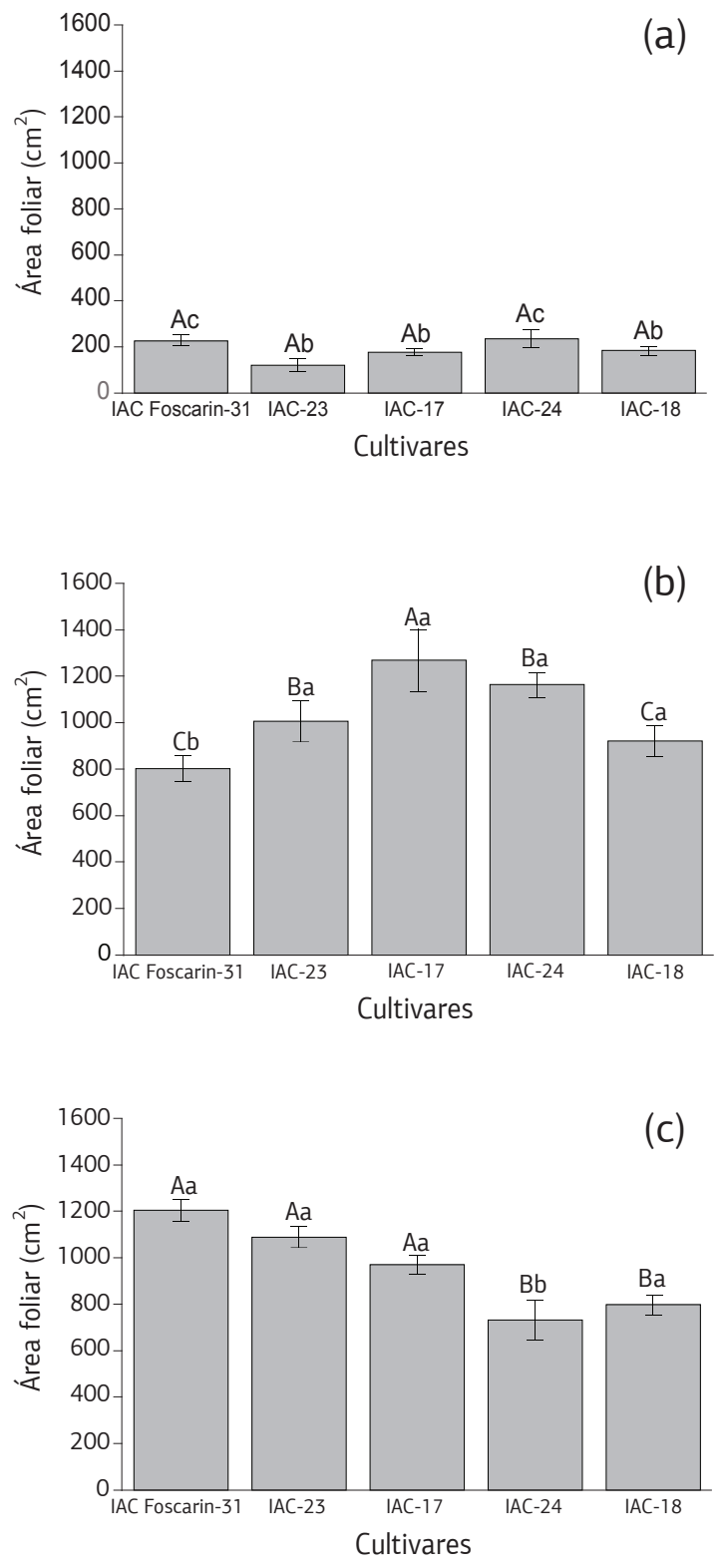

Figura 1. Comparação do aumento em área foliar de cinco cultivares de soja submetidas ao alagamento do sistema radicular durante 28 dias. Análises das plantas alagadas durante 28 dias sem nitrato (a), com nitrato (b) e com nitrato adicionado no dia 7 (c). As barras representam o erro-padrão das médias e as letras, o teste Tukey a $1 \%$ de probabilidade. Os valores apresentados no gráfico foram obtidos a partir do valor final (dia 28) subtraído do valor inicial (dia 0), para cada cultivar. As letras maiúsculas indicam a comparação entre as cultivares para o mesmo tratamento e as letras minúsculas, a comparaçáo entre os tratamentos para a mesma cultivar.

forma condizente com o observado no parâmetro área foliar, no tratamento nitrato adicionado, os maiores valores de massa seca da parte aérea foram observados nas cultivares IAC-23, IAC-17 e IAC Foscarin-31 (Figura 2c). Comparando os tratamentos com nitrato e nitrato adicionado observa-se, na cultivar IAC Foscarin-31, 42,70\% a 
mais de massa seca da parte aérea no tratamento nitrato adicionado em relação ao tratamento com nitrato; na cultivar IAC-24, a massa seca da parte aérea foi de $43,14 \%$ a menos do tratamento nitrato adicionado. Nas cultivares IAC-17, IAC-18 e IAC-23, foi identificado aumento na massa seca da parte aérea nos dois tratamentos em que foi adicionado o nitrato, e não foi identificada diferença significativa entre estes tratamentos. Esses resultados indicam que a adição tardia de nitrato é tão benéfica quanto a adiçáo desde $\mathrm{o}$ início do experimento para as cultivares IAC-17, IAC-18 e IAC-23 (Figura 2).

A massa seca do sistema radicular contribuiu com mais uma evidência de que, no tratamento com nitrato, a cultivar IAC-24 teve melhor desenvolvimento geral que todas as demais cultivares testadas (Figura 3b). Da mesma forma que o observado para os outros parâmetros, no tratamento nitrato adicionado a cultivar IAC Foscarin-31 foi uma das cultivares com a maior massa seca do sistema radicular, nesse caso acompanhada pela cultivar IAC-23. Comparando os tratamentos com nitrato e nitrato adicionado, na cultivar IAC-24, verificam-se valores de massa seca do sistema radicular 53\% maiores no tratamento com nitrato, enquanto nas cultivares IAC Foscarin-31 e IAC-23 os valores foram, respectivamente, $58,84 \%$ e $30,25 \%$ maiores, no tratamento nitrato adicionado. Curiosamente, a adição de nitrato não aumentou a massa seca do sistema radicular da cultivar IAC-18, apesar de ter sido identificado aumento nos parâmetros de parte aérea (Figura 3).

$\mathrm{O}$ volume do sistema radicular foi o único parâmetro avaliado com variação entre as cultivares no tratamento sem nitrato, indicando que o alagamento por si só já é suficiente para evidenciar os efeitos morfológicos diferenciais promovidos pelo alagamento entre as cultivares testadas. Os maiores valores do volume do sistema radicular no tratamento sem nitrato foram apresentados pelas cultivares IAC-24, IAC Foscarin-31 e IAC-23 e todas tiveram evidentes alterações como formação de raízes laterais, raízes adventícias e aerênquima na raiz, em intensidades que variaram de acordo com a cultivar (dados não mostrados). O aumento no número de raízes laterais e na densidade de pelos radiculares sob deficiência de nitrogênio, também foram observados em plantas de tomates sob condiçôes de hipoxia (Horchani e Aschi-Smiti, 2010). Interessantemente, na cultivar IAC-18 não houve diferença significativa no volume do sistema radicular entre os três tratamentos impostos. No tratamento com nitrato as cultivares IAC-24 e IAC-23 obtiveram maior volume do sistema radicular, enquanto no tratamento nitrato adicionado o maior valor foi observado nas cultivares IAC-23 e IAC Foscarin-31 (Figura 4). Os resultados de massa seca do sistema radicular e de volume do sistema radicular deixam claro que a cultivar IAC-23 foi a de maior desenvolvimento do sistema radicular em situação de alagamento e a cultivar que mais proporcionou variaçôes morfológicas
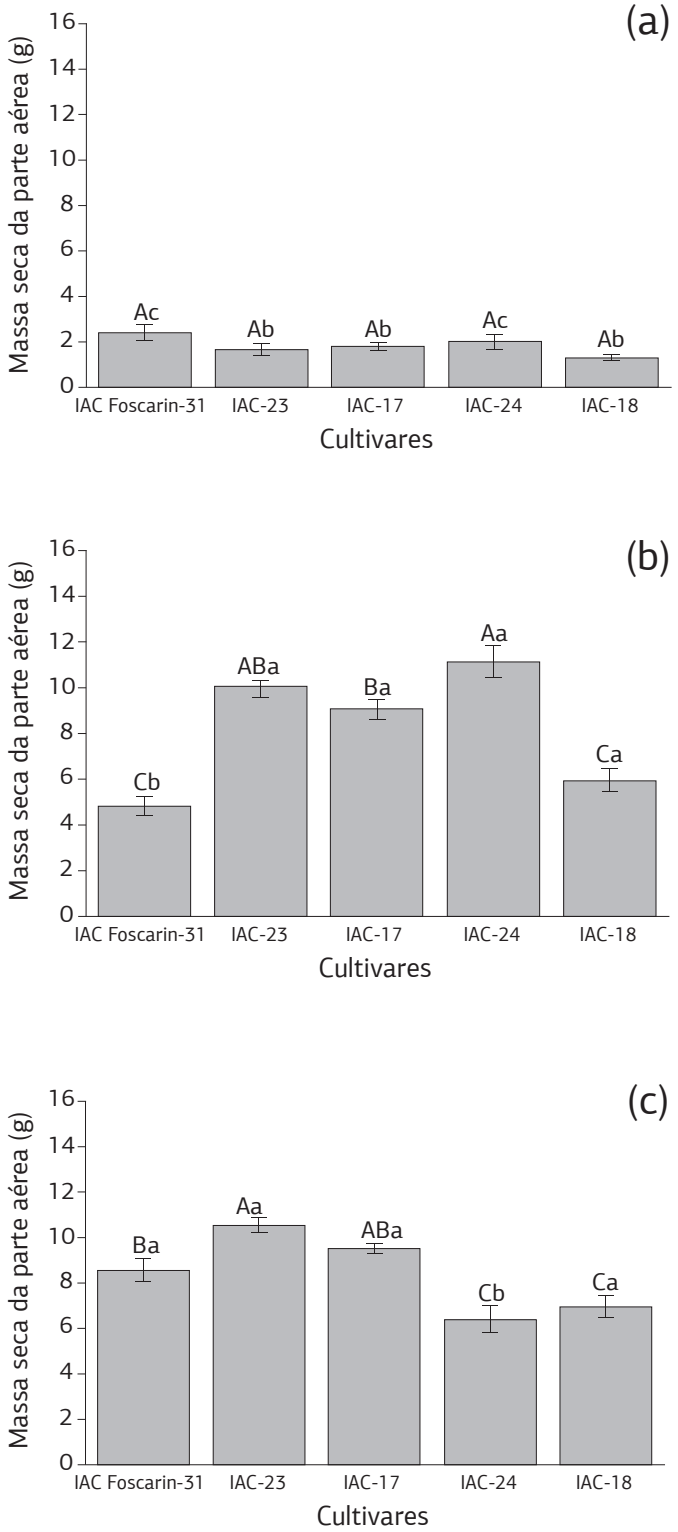

Figura 2. Comparação do aumento da massa seca da parte aérea de cinco cultivares de soja submetidas ao alagamento do sistema radicular durante 28 dias. Análises das plantas alagadas durante 28 dias sem nitrato (a), com nitrato (b) e com nitrato adicionado no dia 7 (c). Os valores apresentados no gráfico foram obtidos a partir do valor final (dia 28) subtraído do valor inicial (dia 0), para cada cultivar. As barras representam o erro-padrão das médias e as letras, o teste Tukey a $1 \%$ de probabilidade. As letras maiúsculas indicam a comparação entre as cultivares para o mesmo tratamento e as letras minúsculas, a comparação entre os tratamentos para a mesma cultivar.

evidentes no sistema radicular em relação à adição de nitrato. Procurando-se evidenciar essas variações, a cultivar IAC-23 foi escolhida para a análise histológica. (Figura 4)

Pela análise histológica de plantas da cultivar IAC-23, observou-se que o caule das plantas-controle estava em estádio secundário de crescimento evidenciado pela formação 

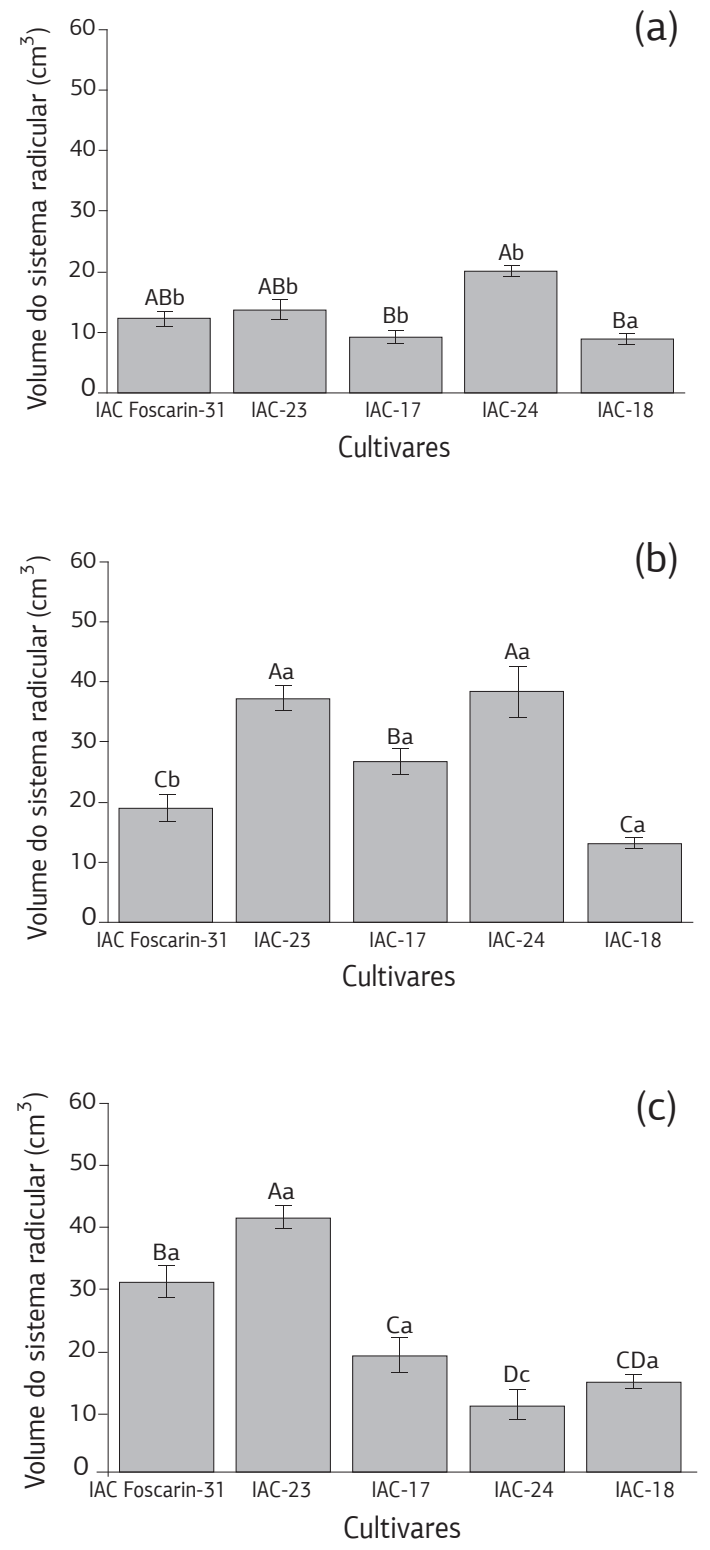

Figura 3. Comparação do aumento do volume do sistema radicular de cinco cultivares de soja submetidas ao alagamento do sistema radicular durante 28 dias. Análises das plantas alagadas durante 28 dias sem nitrato (a), com nitrato (b) e com nitrato adicionado no dia 7 (c). Os valores apresentados no gráfico foram obtidos a partir do valor final (dia 28) subtraído do valor inicial (dia 0), para cada cultivar. As barras representam o erro-padrão das médias e as letras, o teste Tukey a $1 \%$ de probabilidade. As letras maiúsculas indicam a comparação entre as cultivares para o mesmo tratamento e as letras minúsculas, a comparação entre os tratamentos para a mesma cultivar.

de câmbio (ou faixa cambial), além da presença do início da instalação da periderme e lenticelas (Figura 5a). Nas plantas alagadas, que também estavam em estádio secundário de crescimento, células parenquimáticas do córtex e possivelmente células do periciclo se dividiram intensamente formando um tecido com células parenquimáticas de arranjo
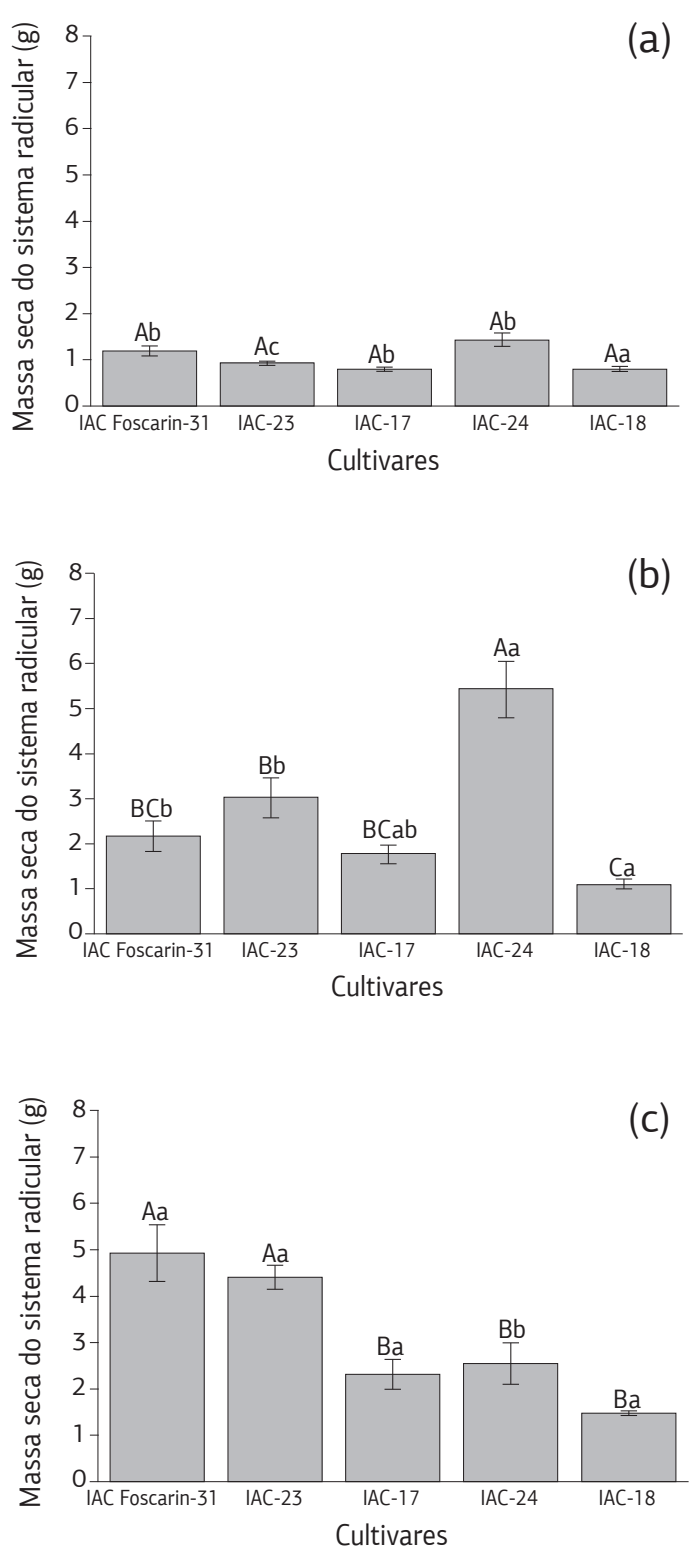

Figura 4. Comparação do aumento da massa seca do sistema radicular de cinco cultivares de soja submetidas ao alagamento do sistema radicular durante 28 dias. Análises das plantas alagadas durante 28 dias sem nitrato (a), com nitrato (b) e com nitrato adicionado no dia 7 (c). Os valores apresentados no gráfico foram obtidos a partir do valor final (dia 28) subtraído do valor inicial (dia 0), para cada cultivar. As barras representam o erro-padráo das médias e as letras, o teste Tukey a $1 \%$ de probabilidade. As letras maiúsculas indicam a comparação entre as cultivares para o mesmo tratamento e as letras minúsculas, a comparação entre os tratamentos para a mesma cultivar.

muito frouxo, o aerênquima (Figuras 5a,c,d). Essa alteração foi observada visualmente e mediante a análise do diâmetro do caule (dados não mostrados). Nas plantas sem nitrato, observou-se o desenvolvimento de fibras de esclerênquima no córtex próximas ao floema (Figura 5b), e a instalação das células em divisão que formaram o aerênquima ocorreu 
externamente a estas fibras (Figura 5b), deslocando partes do córtex. Nas plantas com nitrato, as células em divisão para formar o aerênquima estavam dispostas de maneira mais compacta e o aerênquima formado estava com arranjo menos frouxo que o arranjo das plantas sem nitrato. A adição de nitrato aparentemente forma aerênquima mais compacto, com maior número de células e espaços intercelulares, embora estes espaços sejam menores que nas plantas sem nitrato (Figuras 5a-d).

A raiz principal, assim como o caule, estava em estádio secundário de crescimento (Figura 6a),
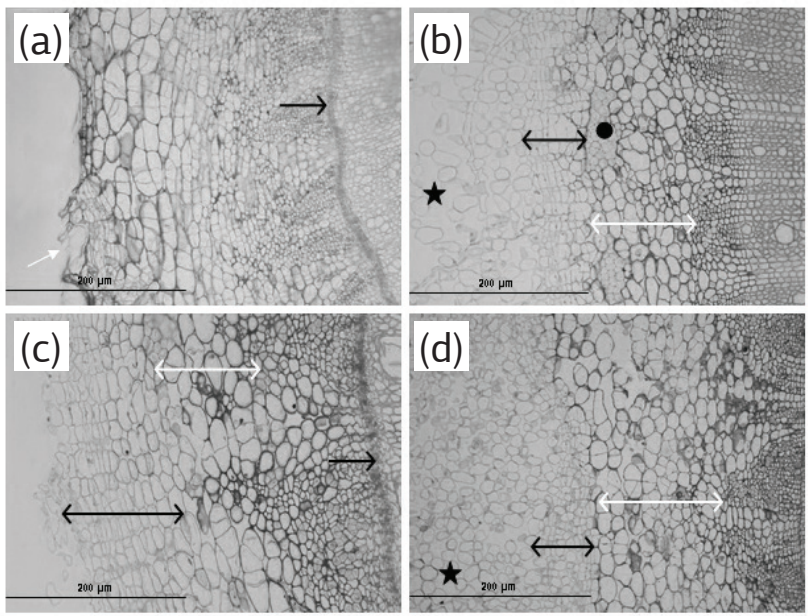

Figura 5. Seçôes transversais do caule de plantas de soja da cultivar IAC-23 alagadas durante 28 dias. (a) controle; (b) plantas alagadas sem nitrato; (c) plantas alagadas com nitrato; (d) plantas alagadas com nitrato adicionado no dia 7. A seta branca indica a lenticela e as setas pretas, a faixa cambial. A região interna às setas duplas pretas mostra as células em divisão para formar o aerênquima e a região interna às setas duplas brancas indica o córtex. O círculo indica as fibras de esclerênquima e a estrela o aerênquima.
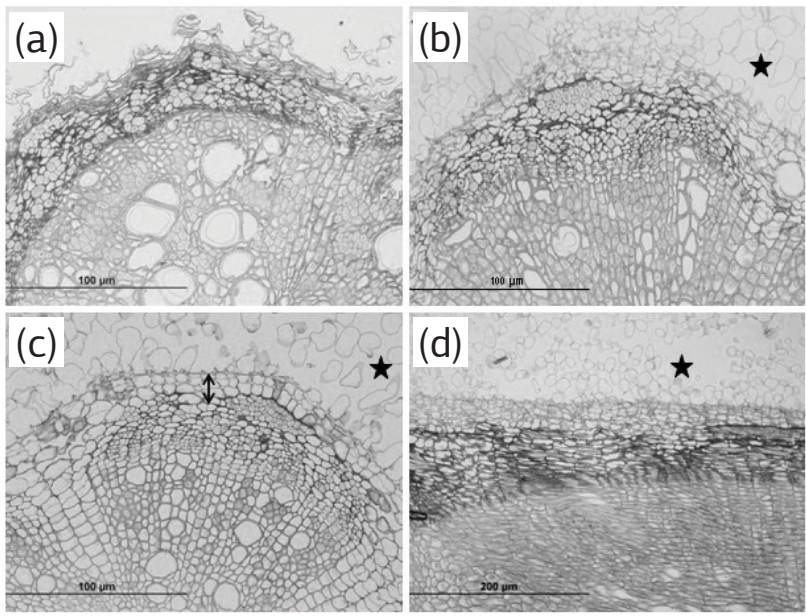

Figura 6. Seçôes transversais da raiz principal de soja da cultivar IAC23 alagadas durante 28 dias. (a) controle; (b) plantas alagadas sem nitrato; (c) plantas alagadas com nitrato; (d) plantas alagadas com nitrato adicionado no dia 7 . A regiáo interna à seta dupla preta compreende células em divisão para formar o aerênquima, e a estrela o aerênquima. constatado pela formaçáo de xilema e floema secundários. Na planta-controle, o córtex estava colapsado devido ao atrito com a vermiculita (Figura 6a). Assim como no caule, o alagamento promoveu a formação de aerênquima a partir de células parenquimáticas do córtex e possivelmente também do periciclo como pode ser observado na figura $6 \mathrm{c}$. No aerênquima formado com a adição de nitrato, assim como no caule, havia células de arranjo mais compacto que nas plantas sem adiçáo de nitrato (Figura 6a-d). De acordo com $\mathrm{He}$ et al. (1994), quando há deficiência de N, ocorre aumento no desenvolvimento do aerênquima pela maior sensibilidade das células corticais ao etileno, causando a quebra mais rápida das células na presença de baixas concentraçôes do gás para formar raízes adventícias. Em experimento realizado por BaCANAMWo e Purcell (1999), os tratamentos com nitrato reduziram o desenvolvimento do aerênquima em $55 \%$, em relação às plantas fixadoras de $\mathrm{N}_{2}$. Embora a inundação na presença de nitrato reduza o aerênquima, este aumenta as raízes adventícias e proporciona aumento de crescimento e da massa seca. Esse efeito pode ter ocorrido neste experimento; no entanto, seria necessário quantificar o aerênquima e as raízes adventícias, o que náo foi realizado. Pires et al. (2002) observou na cultivar de soja FT-Abyara maior formação de tecido aerenquimatoso, o que explicou, em parte, o maior crescimento desta cultivar em condiçóes de alagamento em relação à cultivar BR4. Thomas et al. (2005) observaram em plantas de soja noduladas a formação de aerênquima, inicialmente no córtex, e posteriormente substituído por aerênquima secundário, derivado de células parenquimáticas e possivelmente do periciclo. Neste experimento só foi observada a formação do aerênquima secundário a partir também de células parenquimáticas e do periciclo.

Os resultados analisados em conjunto demonstram que a presença de nitrato auxilia no desenvolvimento das plantas de soja em situação de alagamento e que a intensidade da resposta ao nitrato varia com a cultivar. Considerando a adição do nitrato desde o início do alagamento, pode-se considerar a cultivar IAC-24 como a cultivar com o maior crescimento, e, portanto, a que tem a melhor resposta a essa situação. De forma curiosa, a IAC-24 não respondeu bem ao tratamento nitrato adicionado, notando-se os menores valores em alguns parâmetros avaliados. De forma oposta, a cultivar IAC Foscarin-31 foi a que melhor respondeu ao tratamento nitrato adicionado, apesar de não ter se desenvolvido táo bem quanto as outras quando submetida ao tratamento com nitrato. Nas cultivares IAC-17 e IAC-23, é claro que a aplicação de nitrato é benéfica em situação de alagamento, entretanto, a fase em que o nitrato é aplicado não influencia na resposta das cultivares. A cultivar IAC-18 
proporciona melhor resposta de crescimento na parte aérea e não ocorre variação significativa no sistema radicular em presença de nitrato. É interessante a observação de que o padrão de resposta ao nitrato entre as cultivares varia, e, além disso, o momento de aplicação do nitrato é importante no caso das cultivares IAC-24 e IAC Foscarin-31. Uma das possíveis explicaçóes para esse fato é que as cultivares têm diferentes estratégias para amenizar os danos do estresse sofrido e continuar o seu desenvolvimento. Dentre estas estratégias, os resultados deixam claro que o desenvolvimento da parte aérea, do sistema radicular e o surgimento de modificações como aerênquimas, raízes adventícias e pelos radiculares, são fundamentais nos mecanismos de tolerância. A intensidade das modificaçôes depende da adaptação de cada cultivar à condição de alagamento. De acordo com a definição de adaptação sugerida por Pires et al. (2002) e Zenzen et al. (2007), a cultivar com maior desenvolvimento em cada um dos tratamentos pode ser considerada como a mais adaptada àquela situação.

\section{CONCLUSÃO}

A presença do nitrato desde o início do alagamento ou adicionado sete dias após o alagamento é benéfica para as cinco cultivares estudadas e auxilia no desenvolvimento das plantas de soja. A intensidade de resposta ao nitrato varia com a cultivar.

A IAC-24 é a cultivar com maior crescimento da planta em condiçóes de alagamento na presença de nitrato desde o início do alagamento. Com a adição de nitrato sete dias após alagamento o maior crescimento é obtido com a cultivar IAC Foscarin-31. A cultivar IAC Foscarin-31 proporciona a melhor resposta sob a condição de adiçáo de nitrato sete dias após alagamento, dentre todas as cultivares testadas. Na cultivar IAC-23, há maior desenvolvimento do sistema radicular em presença de nitrato, com formação de aerênquimas e raízes adventícias. A cultivar IAC-18 prioriza o desenvolvimento da parte aérea em detrimento do desenvolvimento do sistema radicular em situação de alagamento com adição de nitrato.

A presença de aerênquima no caule e na raiz principal de plantas alagadas é constatada em todos os tratamentos, porém há variação no arranjo das células parenquimáticas, o qual é mais compacto nos tratamentos com nitrato.

\section{AGRADECIMENTOS}

Agradecimento à Coordenação de Desenvolvimento de Pessoal de Nível Superior (Capes) e ao Conselho Nacional de Desenvolvimento Científico e Tecnológico (CNPq) pelo auxílio financeiro.

\section{REFERÊNCIAS}

ARMSTRONG, W.; BRANDLE, R.; JACKSON, M.B. Mechanisms of flood tolerance in plants. Acta Botanica Neerlandica, v.43, p.307$358,1994$.

BACANAMWO, M.; PURCELL, L.C. Soybean root morphological and anatomical traits associated with acclimation to flooding. Crop Science, v.39, p.143-149, 1999.

BORKERT, C.M.; YORINORI, J.T.; CORREIA-FERREIRA, B.S.; ALMEIDA, A.M.R.; FERREIRA, L.P.; SFREDO, G.S. Seja o doutor da sua soja. Informações agronômicas, v.66, p.1-6, 1994.

BRANDÃO, A.D.; SODEK, L. Nitrate uptake and metabolism by roots of soybean plants under oxygen deficiency. Brazilian Journal of Plant Physiology, v.21, p.13-23, 2009.

CONAB. Acompanhamento da safra brasileira: grãos, quinto levantamento. Disponível em: <http://www.conab.gov.br>. Acesso em: 9/2/2012.

FANTE, C.A.; ALVES, J.D.; GOULART, P.F.P.; DEUNER, S.; SILVEIRA, N.M. Respostas fisiológicas em cultivares de soja submetidas ao alagamento em diferentes estádios. Bragantia, v.69, p.253-261, 2010.

FEDER, N.; O'BRIEN, T.P. Plant microtechnique: some principles and new methods. American Journal of Botany, v.55, p.123-142, 1968.

IBAMA. Relatório perspectivas do meio ambiente mundial. Estado do meio ambiente e retrospectivas políticas: 1972-2002. Disponível em: <http://www2.ibama.gov.br>. Acesso em: 9/2/2012.

HE, C.; DREW, M.C.; MORGAN, P.W. Induction of enzymes associated with lysogenous aerenchyma formation in roots of Zea mays during hypoxia or nitrogen starvation. Plant Physiology, v.105, p.861865, 1994.

HOAGLAND, D.R.; ARNON, D.I. The water culture method for growing plants without soil. California Agricultural Experimental Station, v.347, p.1-39, 1938.

JOHANSEN, D. Plant Microtechnique. New York: McGraw-Hill, 1940. 523p.

HORCHANI, F.; ASCHI-SMITI, S. Prolonged root hypoxia effects on enzymes involved in nitrogen assimilation pathway in tomato plants. Plant Signaling and Behavior, v.5, p.1583-1589, 2010 .

LENHARD, N.R.; SCALON, S.P.Q.; NOVELINO, J.O. Crescimento inicial de mudas de pau ferro (Caesalpinia férrea Mart. ex Tul. var. leiostachya Benth.) sob diferentes regimes hídricos. Ciência e Agrotecnologia, v.34, p.870-877, 2010.

MALAVOLTA, E. Studies on the nitrogenous nutrition of rice. Plant Physiology, v.29, p.98-99, 1954.

OLIVEIRA, H.C.; SALGADO, I.; SODEK, L. Involvement of nitrite in the nitrate-mediated modulation of fermentative metabolism and nitric oxide production of soybean roots during hypoxia. Planta, v.237, p.255-264, 2013. 
PIRES, J.L.F.; SOPRANO, E.; CASSOL, B. Adaptaçôes morfofisiológicas da soja em solo inundado. Pesquisa Agropecuária Brasileira, v.37, p.41-50, 2002.

REIS, I.N.R.S.; SANTOS-FILHO, B.G.; CASTRO, C.V.B.; LAMEIRA, C.N.; ROSSATO, V. Análise de crescimento e produção de biomassa de plantas jovens de curauá (Ananas erectifolius L. B. Smith) submetidas ao alagamento. Revista Brasileira de Biociências, v.5, p.504-506, 2007.

THOMAS, A.L.; GUERREIRO, S.M.C.; SODEK, L. Aerenchyma formation and recovery from hypoxia of the flooded root system of nodulated soybean. Annals of Botany, v.96, p.1191$1198,2005$.

THOMAS, A.L.; SODEK, L. Development of the nodulated soybean plant after flooding of the root system with different sources of nitrogen. Brazilian Journal of Plant Physiology, v.17, p.291-297, 2005.

TROUGHT, M.C.T.; DREW, M.C. Alleviation of injury to young wheat plants in anaerobic solution cultures in relation to the supply of nitrate and other inorganic nutrients. Journal of Experimental Botany, v.32, p.509-522, 1981.

YORINORI, J.T. Cancro da haste da soja: epidemiologia e controle. Londrina: EMBRAPA-CNPSo, 1996. 75p.

ZENZEN, I.L.; AMARANTE, L.; COLARES, D.S.; OLIVEIRA, M.L.; BERNARDI, E.; COSTA, E.L.G.; NASCIMENTO, J.S. Área foliar e volume do sistema radicular em plantas de soja inoculadas com estirpes de Bradyrhizobium e submetidas ao alagamento. Revista Brasileira de Biociências, v.5, p.1092-1094, 2007. 